\title{
A Low Memory 3D Animation Technology for "Animation Design" Course
}

\author{
http://dx.doi.org/10.3991/ijet.v11i05.5697 \\ Zhenyan Qin, Zonghua Tao \\ Anhui Sanlian University, Hefei, Anhui, China
}

\begin{abstract}
This paper introduces a "low memory" 3D animation design technology teaching system, and fully describes the design requirements, design thought, and main modules of the system. On this basis, an analysis of the teaching process of applying the system in animation design curriculum in universities is made with the method of contrastive teaching experiment. Results show: comparing with traditional multimedia teaching method, the application of "low memory" 3D animation design technology significantly improves the effectiveness of animation design teaching. This teaching method is of prominent innovative value, and worth to be further popularized and applied in teaching.
\end{abstract}

Index Terms-Low memory, 3D animation, animation design, teaching experiment

\section{INTRODUCTION}

Three-dimensional animation design technology, also referred to as 3D animation technology, is a virtual information technology that emerged in recent years. With this technology, it can be realized to build a virtue threedimensional world in computer. The said threedimensional world acts as a design platform for designers. Designer, based on the models and scenes provided in the three-dimensional world, describes and designs the motion track and other animation parameters of objects with professional software index, adds light, color and other elements, and submits the foregoing to computer for automatic calculation. Finally, three-dimensional animation scenes are be generated [1]. On the whole, threedimensional animation design technology is featured by accuracy, lifelikeness, and dynamics, etc., and is widely used in medical science, education, military, architecture, etc. $[2,3]$. The research and practice of the application of three-dimensional animation design technology in education has gradually become a hot topic that both Chinese and foreign education experts are keen on in recent years. For example, Zhou Q and Liu C applied three-dimensional technology in architecture curriculum teaching, believing that students can see lifelike buildings in classroom with the help of three-dimensional technology, which helps students' understanding and recognition. Besides, 3ds Max modeling software is adopted to build an expander model for the unit. According to the method of impeller modeling, the modeling method chosen in the paper is verified to be practical. Results show that the $3 \mathrm{ds}$ Max software technology is superior in the application of multimedia teaching [4]. Some educators introduced threedimensional technology into English teaching, building a visual three-dimensional digital stage with threedimensional spectrum technology, 3DS MAX and Cult3D. The digital stage forms a comprehensive, innovative, interactive and practical communication platform for students learning tourism English, and its application has been proved to be practical [5]. Some medical educators tried to apply three-dimensional technology in surgical teaching. They apply virtual-realistic simulation in spine surgery. With respect to virtual simulation, 3D videos on some spinal surgical approaches were made; with respect to physical simulation, a lumbar spine model as similar as possible to the patient's anatomy was built. According to the experimental results, this virtual simulation effectively facilitates working with 3D data, and greatly improves teaching of surgical anatomy and operative strategies in the neurosurgical and orthopaedic fields. [6] Sun Yi discussed the process of BIM three-dimensional animation demonstration technology in architecture teaching in higher vocational colleges, and introduced specific teaching strategies [7]. Zhang Qiaoling analyzed the application of three-dimensional animation technology in anatomy teaching in universities [8]. Liu Diyu analyzed the method of applying Cult3D technology in mechanical drawing teaching in higher vocational colleges, pointing out: the introduction of three-dimensional technology can inspire students' learning interest better, highlight key teaching points, and help students to construct a clear threedimensional space concept and consciousness [9].

According to the research results of the abovementioned scholars, it is not hard to find that threedimensional animation design technology has gradually become a new direction of curriculum innovation in university teaching. Some researchers, however, pointed out that most three-dimensional animation technology teaching platforms have a problem of inconvenience in animation demonstration and video filming. For example, if a teacher intends to record the three-dimensional changing scenes during the motion of animation objects in teaching process, usually there is cellphone or film recording software that can be resorted to. Besides, the videos filmed in this way should be converted into rmvb, avi, flv and such with professional video converter, so as to be displayed to students [10]. It is thus clear that the abovementioned teaching process has at least two defects. First, it is complicated to film videos, and post production and conversion are required, undoubtedly making teaching demonstration difficult. Second, the size of converted threedimensional animation video is usually large and occupies a large memory space, while the memory space of teaching platform is not large enough [11].

To effectively solve the aforesaid problems, the teaching system is designed to build a animation recording device for teaching demonstration of high speed and low consumption by giving priority to "low memory" and "fast video filming", and integrating three-dimensional 
animation design technology into teaching. With such a device, the data size of teaching video is remarkably reduced, and the use ratio of the storage space of the system rises. First, the "low memory" three-dimensional technology animation recording device in this research can reduce the data size of three-dimensional scene animation videos, and then increase the use ratio of storage space. Second, "low memory" three-dimensional animation design technology teaching system is applied in the teaching of animation design as an innovation. The paper mainly discusses the requirement analysis, design thought and module structure of the teaching system. On this basis, the paper also goes into the feasibility and necessity of the application of the three-dimensional animation design technology in the teaching of animation design, and discusses the promotional value of this teaching method based on the experimental analysis results.

\section{OVERVIEW OF "LOW MEMORY" THREE- Dimensional ANimation Design TECHNOLOGY TEACHING SYSTEM}

\section{A. Design thought}

According to the design, the teaching system is based on three-dimensional animation technology, adopts program compiling, multimedia framework and information components to integrate the theory and practical curriculum contents of animation design, and displays relevant contents in the animation design curriculum to students by means of three-dimensional animation demonstration, recording, and playing. Students can make and upload their own animation design works via the teaching system, to realize communication in class between students and teachers, and among students. Besides, the system adopts a convenient man-machine conversation function, with which teachers can deliver lectures to students in a convenient, entertaining and dynamic way via touch screen, voice actions, video playing, video filming and video sharing, etc. Based on the foregoing descriptions, the animation teaching video design framework of the system can be drawn as figure 1 .

Figure 1 is a flow block diagram of animation video filming of the three-dimensional animation teaching system. Based on the above flow mode, five procedures are to be handled to make a teaching video with the system, namely receiving instructions, adjusting parameters, acquiring timestamps, storing timestamps, compressing and saving video. The detailed introduction is as follows:

(1) Receiving instructions: receive an instruction of recording, and rapidly build corresponding 3D scenes.

(2) Adjusting parameters: the system automatically adjusts output parameters in a self-diagnosis mode based on the requirements of the animation teaching video to be filmed.

(3) Acquiring timestamps: acquire and collect the timestamps of describing parameters of the said animation scenes.

(4) Storing timestamps: store the describing parameters of the said animation scenes and the corresponding timestamps.

(5) Compressing and saving video: Compress the filmed animation video into a rational size, and automatically save it.

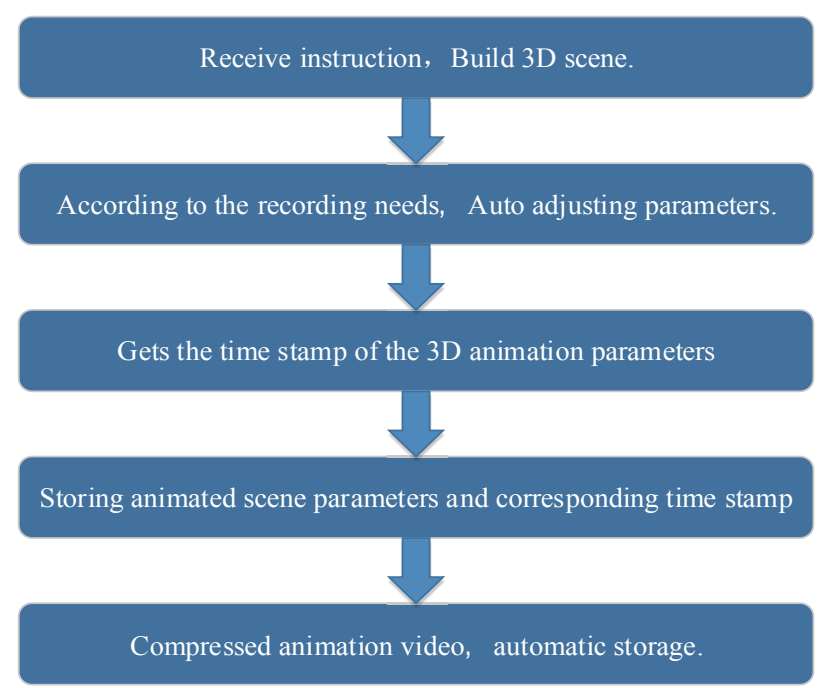

Figure 1. Making diagram of network interactive teaching material

In order to prevent the video from occupying excessive system memory, an H.265 video compression technology was especially adopted in the aforesaid process. This technology is featured by high bit rate and low bandwidth, and can significantly increase the definition of video and effectively reduce the size of video, realizing the original design objectives of "low memory".

\section{B. Module structure}

Based on the design thought as above, the modules of the three-dimensional animation design teaching system are designed as figure 2 .

As shown in the figure 2, the teaching platform consists of multiple modules and has many functions, including video recording, video compression, demonstration via touch screen, timely playing, voice setting, etc. In the teaching of animation design curriculum, teachers can make an integrated use of the aforesaid module functions. The production, playing and sharing of animation videos required for the teaching of animation technology curriculum can be conducted by inputting video information, creating video scenes, compressing video size, and operation via touch screen or vocal control, and interaction with students can be carried out. Comparing with traditional three-dimensional animation design teaching platform, the system is superior in teaching application in respect of intellectuality, energy saving, convenience and speed.

\section{TEACHING EXPERIMENT AND APPLICATION ANALYSIS}

\section{A. Object and method}

223 sophomores from 4 classes of a university were taken for contract experiment. 2 classes were taken as the control group (113 students), and the other 2 classes as the experimental group (110 students). The differences between students in the control group and in the experimental group in respect of sex, age and mathematical foundation (higher mathematics) are of no statistical significance $(\mathrm{P}>0 \square 05)$, and the previous comprehensive assessments and the assessments on the class atmosphere from teachers of classes in both group show that the students in both groups are commensurate with each other in respect of learning ability and attitude. Hence, the two groups are comparable. 


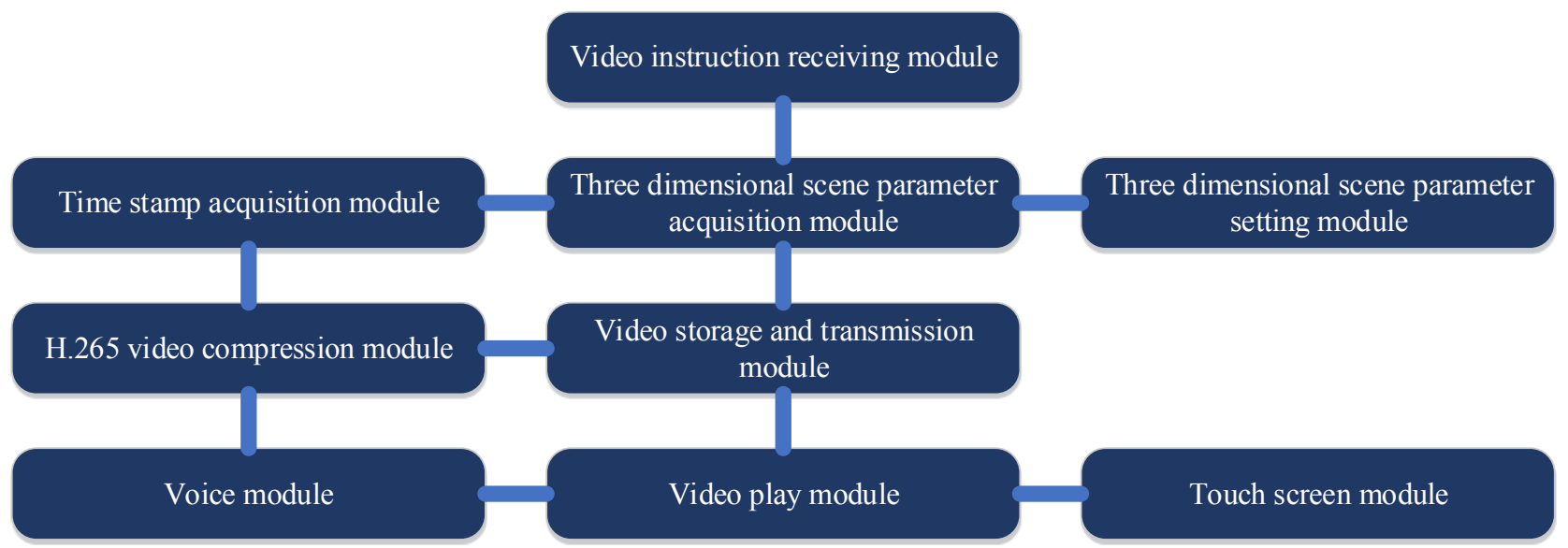

Figure 2. Module structure diagram of three-dimensional animation design teaching system

\section{B. Teaching design}

The curriculum of animation design was taken as the teaching contents. The teaching period of the curriculum is 32 class hours. A teaching method of combining theories with practice was adopted. The exam results and learning cognition of students in both groups were collected and analyzed by means of questionnaire and quantitative statistics after the 32-class-hour teaching period is finished. The effectiveness of "low memory" threedimensional animation design technology in animation design teaching was evaluated on this basis.

\section{Statistical method}

SPSS software was adopted to make a sample analysis of the exam results of students. $\mathrm{P}<0.05$ means that the difference is of statistical significance. Besides, EXCEL software was adopted to conduct data statistics on the learning cognition of students, and charts were drawn for analysis on this basis. In this way, the teaching evaluation results were clearly presented.

\section{TEACHING Mode}

\section{A. Teaching mode for control group}

In the teaching in the control group, teacher adopted traditional "PPT demonstration teaching method", namely: implementing teaching with multimedia courseware as the teaching carrier, and in combination with oral interpretation, in-class question answering, and assignments.

\section{$B$. Teaching mode for experimental group}

In the teaching in the experimental group, teacher adopted a "low memory" three-dimensional animation design technology platform, and organized and designs a "stage-based theory-practice integration" teaching mode for purpose of teaching practice, of which the specific process is as follows:

(1) Guide teaching via demonstration

At this stage, teacher introduced cases to students via the "low memory" three-dimensional animation design technology platform. In the implementation of teaching, teacher input multiple animation design works via the touch screen and vocal control of the platform, to guide students to observe, and showed the steps of animation scene creating and animation video filming with the maya software integrated via the platform.

(2) Cooperative learning among a team

After demonstration, teacher divided students into several teams based on the learning abilities of students and in the principle of hierarchical composition, sent the teaching videos made at [Stage I] to the computer terminal of every team via the LAN in classroom, guided students to watch the videos again, and asked students to independently try to produce and film animation videos with the "low memory" three-dimensional animation design technology platform through cooperation with teammates according to the steps as shown in videos. In this process, teacher was required to properly give technical guidance.

(3) In-class presentation of works

After all teams had finished animation work design and video producing, teacher created a text file in his/her personal computer for the teams to upload their works via the LAN. After all works were received, teacher integrated the works of the teams into one video via the "low memory" three-dimensional animation design technology platform, and presented the integrated video to students via the multimedia system. Each team elected a representative to act as judge, to comment and rank the videos.

(4) Summarization and sharing of exam results

In order to obtain a better teaching effect, teacher designed an in-class test link, covering both theories and operation, and asked students to finish the "theory-practice integration" test based on their gains in previous leaning and practice. Thereafter, teacher uploaded all resources on the class to the LAN platform for sharing, and guided students to have summative learning after class. (see figure 3 , figure 4 and figure 5) 


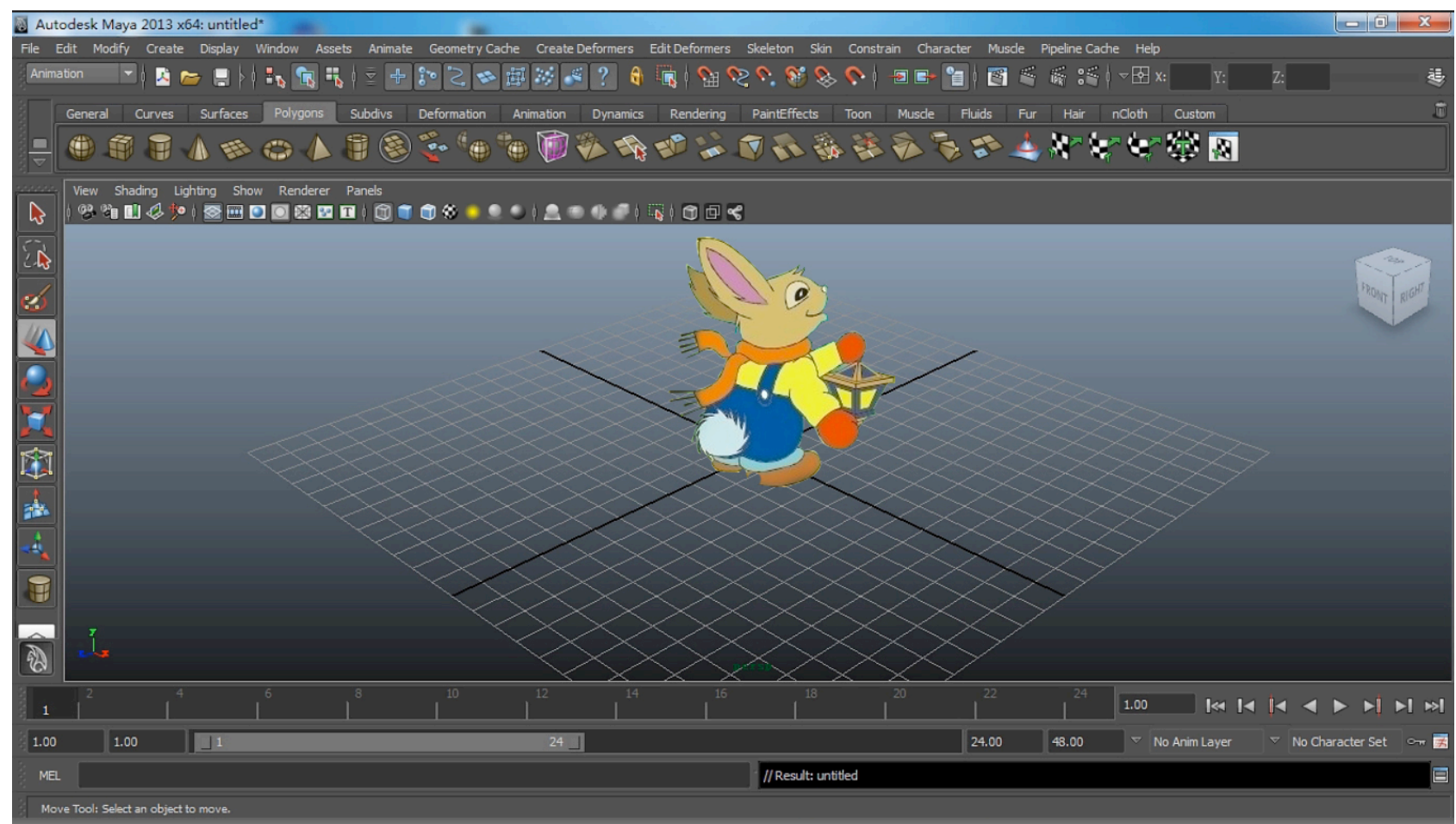

Figure 3. The making process of "low memory" 3D animation technology

\section{D technology teaching platform}
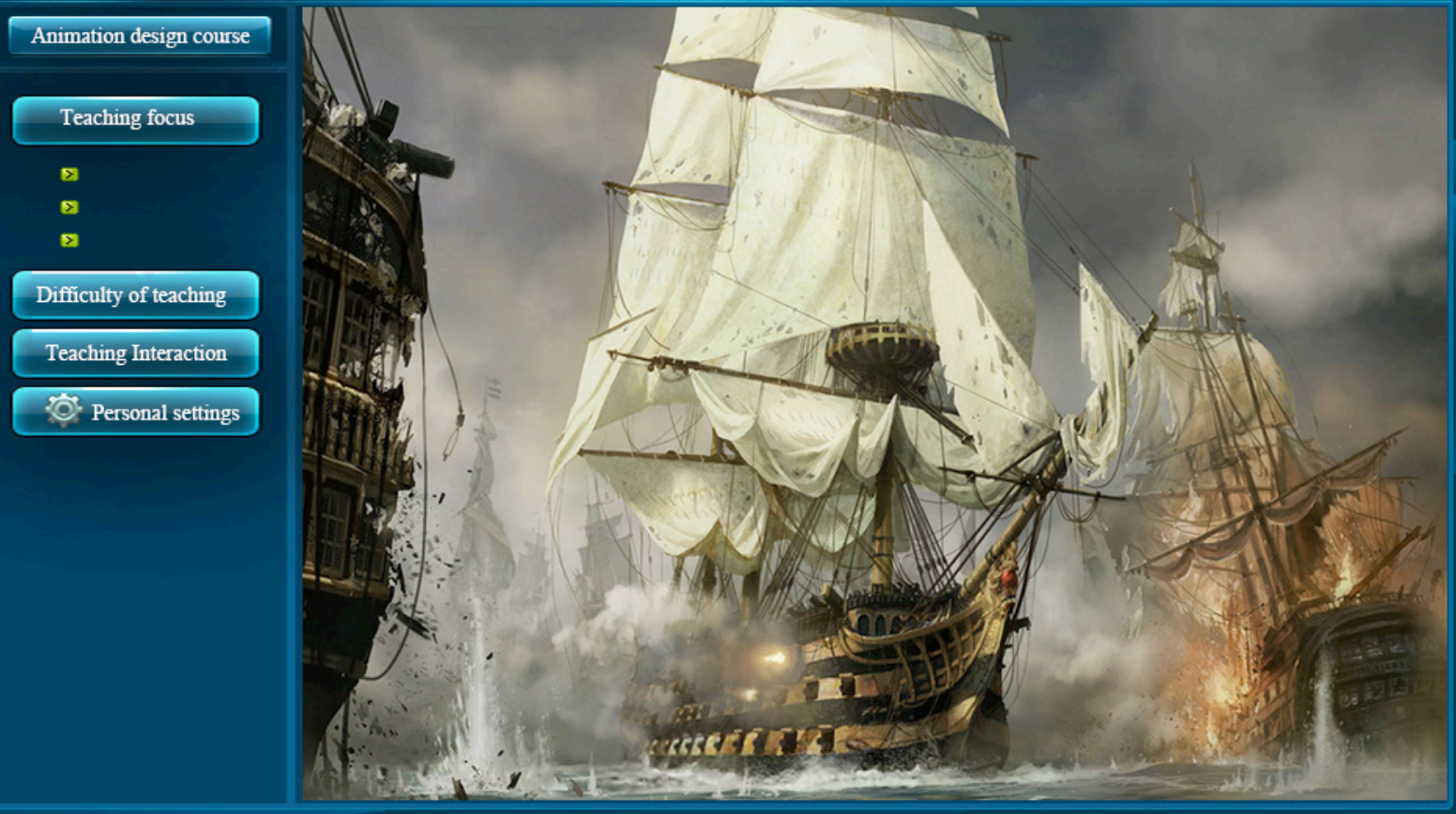

Last

Next

Exit

Figure 4. The course of "low memory" 3D animation technology 
PAPER

A Low Memory 3D Animation Technology for “Animation Design” Course

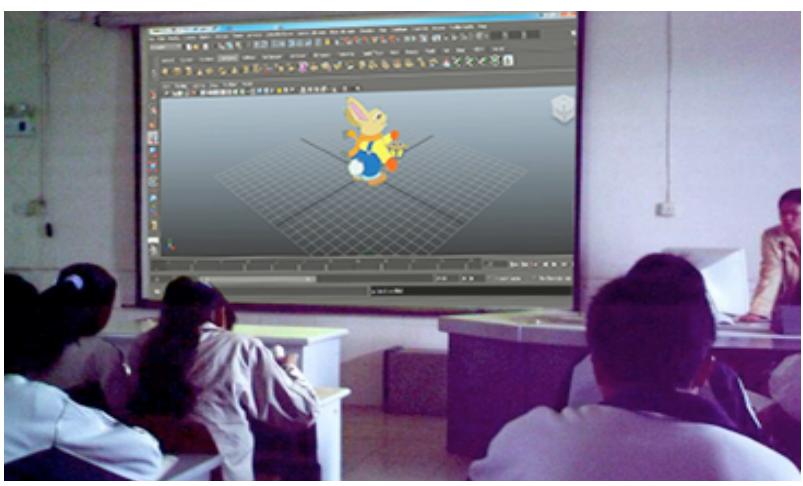

Figure 5. Interaction between teachers and students of "low memory" $3 \mathrm{D}$ animation technology

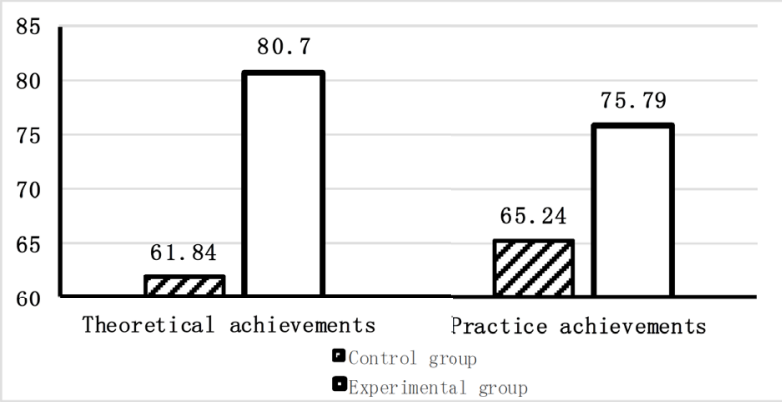

Figure 6. Comparison of examination results of experimental group and control group

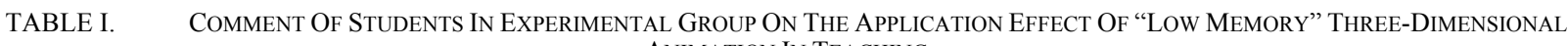
ANIMATION IN TEACHING

\begin{tabular}{|c|c|c|c|}
\hline Question & No & Yes & $\mathbf{P}$ \\
\hline $\begin{array}{l}\text { Are the difficulties and key points of animation design knowledge understood easier with the help of "low } \\
\text { memory" three-dimensional animation? }\end{array}$ & $13(20.97)$ & $97(16.22)$ & $<0.001$ \\
\hline $\begin{array}{l}\text { Is it true that "low memory" three-dimensional animation can help teacher to deliver lectures more interest- } \\
\text { ingly and inspire your learning interest? }\end{array}$ & $9(14.52)$ & 101(16.89) & $<0.001$ \\
\hline Can "low memory" three-dimensional animation help you to concentrate in class? & $13(20.97)$ & $97(16.22)$ & $<0.001$ \\
\hline Can "low memory" three-dimensional animation help teacher to make classroom atmosphere more active? & $5(8.06)$ & $105(17.56)$ & $<0.001$ \\
\hline Can "low memory" three-dimensional animation help students to raise learning efficiency? & $16(25.81)$ & $94(15.72)$ & $<0.001$ \\
\hline $\begin{array}{l}\text { Does presenting knowledge points with "low memory" three-dimensional animation make for knowledge } \\
\text { memorizing? }\end{array}$ & $6(9.68)$ & $104(17.39)$ & $<0.001$ \\
\hline
\end{tabular}

\section{Teaching effect}

Figure 6 is about the statistical analysis of the theory test results and practice examination results of students in both groups after the 36-class-hour teaching period. The results show that the theory and practice test results of students in the experimental group are remarkably superior to that in the control group $(\mathrm{P}<0.01)$ ( as shown in Figure 3$)$. The theory test results of the control group and the experimental group are $61.84 \pm 5.49$ and $80.7 \pm 6.77$ respectively, and the practice examination results are $65.24 \pm 6.98$ and $75.79 \pm 7.66$ respectively. It is thus clear that the application of "low memory" three-dimensional animation design technology has indeed remarkably improved the teaching effectiveness.

Questionnaire method was adopted to students in the experimental group to evaluate the effect of the application "low memory" three-dimensional animation design technology in animation design teaching. For this purpose, 109 questionnaires were handed out, and 109 questionnaires were received. The number of valid questionnaires is 109 , and the validity rate reaches $100 \%$.

According to Table 1, the students in the experimental group speak highly of the effect of "low memory" threedimensional animation in teaching. Most students $(\mathrm{P}<0.001)$ believe that "low memory" three-dimensional animation can make for students understanding the difficulties and key points of curriculum knowledge, inspire students' learning interest, help students to concentrate in class, light classroom atmosphere, and help students to raise learning efficiency and memorize knowledge.

\section{CONCLUSIONS}

Animation design is a required course for animation production majors in colleges and universities. Animation design falls into the sector of CG (Computer Graphics), and is a special visual artistic creation mode mainly realized though $2 \mathrm{D}, 3 \mathrm{D}$ or animation effect or such technique of expression by combining animation and cartoon comics with stories. In traditional teaching mode, teacher usually delivers lectures with the help of PPP demonstration. This mode is relatively well-developed, but lacks innovation and interestingness. It is hard to inspire students' interest with the traditional teaching mode. If it continues this way, it is unfavorable to improving teaching effectiveness. This paper researches and designs a "low memory" three-dimensional animation design technology platform. This platform consists of animation video producing module, voice recognition module, playing and demonstration module, touch screen operation module, etc. The videos produced via this platform cover a small system memory space, and played conveniently and easily. Concerning interaction between teachers and students, a "stage-based theory-practice integration" teaching mode was designed based on the characteristics of the teaching system, in which progressive teaching is conducted at four stages, students are trained to form a capability of animation design via the system. Teaching practices prove that applying this system in teaching can remarkably improve students' academic performance. Besides, the adoption of "low memory" three-dimensional animation design technology also is of positive significance to optimizing students' learning cognition. Animation technology provides a good platform for statistics teaching. Specifically, embodying key knowledge points and difficulties by 3D animation can arouse students' interest as far as possible, and inspire their learning enthusiasm and initiative, so as to raise learning efficiency.

To sum up, introducing "low memory" threedimensional animation design technology in animation design teaching in universities can greatly improve students' academic performance and stimulate students' learning interest. 
PAPER

\section{A Low Memory 3D Animation TeChnology for “Animation Design” Course}

\section{REFERENCES}

[1] Reinhart C., Breton P.F., "Experimental validation of Autodesk ${ }^{\circledR}$ 3ds Max ${ }^{\circledR}$ Design 2009 and DAYSIM 3.0," Leukos, vol. 6, no. 1, pp. 7-35, September 2013.

[2] Combs R.M., Mazur J., "3D Modeling in a High School Computer Visualization Class: Enacting," Cases on 3D Technology Application and Integration in Education, pp. 359, 2013. http://dx.doi.org/10.4018/978-1-4666-2815-1.ch015

[3] Rawi N.A., Zaman H.B., Ahmad A., "Design of Class Components for Laparoscopy Surgery Simulation with Haptic Elements: A Case Study of SPLasH," Lecture Notes on Software Engineering, vol. 1, no. 3, pp. 323, September 2013. http://dx.doi.org/10.7763/LNSE.2013.V1.70

[4] Zhou Q., Liu C., "With Expander Three-Dimensional Model as an Expander, Application of 3DS Max Technology in Multimedia Teaching," Applied Mechanics and Materials, vol. 525, pp. 759762, October 2014. http://dx.doi.org/10.4028/www.scientific.net/ AMM.525.759

[5] Luo Y., "Application of the 3D Visual Digital Stage in Tourism English Teaching," Journal of Ningbo University (Educational Science Edition), vol. 35, no. 1, pp. 99-102, February 2013.

[6] Coelho G., Segundo S., Wen C.L., Lyra M., Barros Filho T., Defino H., "Board 131-Program Innovations Abstract The Combination of Virtual and Realistic Anatomical Models in Spine Surgical Training," Simulation in Healthcare, vol. 8, no. 6, pp. 419-420, December 2013. http://dx.doi.org/10.1097/01.SIH.0000441396. 85500.74

[7] Sun Y., "Application of BIM 3D Animation Demonstration Technology in Architecture Teaching in Higher Vocational Colleges,"
Course Education Research, vol. 2, no. 32, pp. 241, Novermber 2013.

[8] Zhang Q.L., "Application of 3D Animation Technology in Anatomy Teaching," Heilongjiang Animal Science and Veterinary Medicine, vol. 36, no. 6, 166-167, March 2013.

[9] Liu D.Y., "Research on the Aid of 3D Animation Technology in Mechanical Drawing Teaching in Higher Vocational Colleges," Contemporary Vocational Education, no. 12, pp. 42-45, December 2013.

[10] Bentley J., Van Mele P., Okry F., Zossou E., "Videos that speak for themselves: when non-extensionists show agricultural videos to large audiences," Development in Practice, vol. 24, no. 7, pp. 921-929, September 2014. http://dx.doi.org/10.1080/09614524. 2014.942216

[11] Wang J., Wu Y.H., Duan Y., Ji J., "Penetration into Innovation of 3D Technology Application in Education," Modern Distance Education Research, vol. 22, no. 1, pp. 62-71, February 2015.

\section{AUTHORS}

Zhenyan QIN is a Lecturer of Anhui Jianzhu University, Hefei 230022, Anhui, China. Her research interests include 3D Animation. (zhenyanqin66@yeah.net)

Zonghua TAO is a lecturer of Anhui Sanlian University, Hefei 230601, Anhui, China. His research interests include 3D Animation Design. (yingyushiping@126.com)

Submitted 29 March 2016. Published as resubmitted by the authors 09 May 2016. 